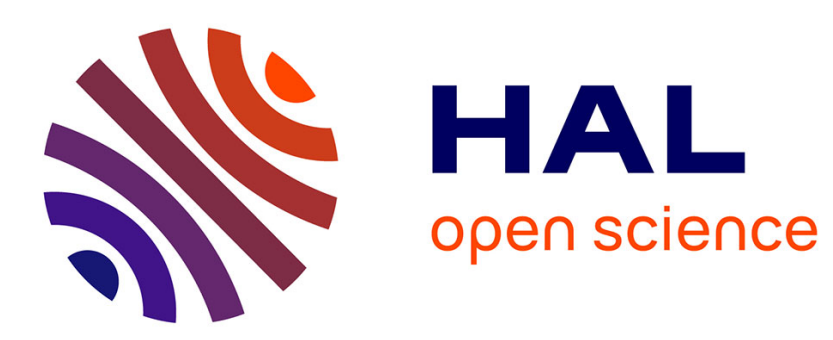

\title{
A metabolic switch is involved in life-style decisions in Photorhabdus luminescens
}

\author{
Lea Lango, David Clarke
}

\section{To cite this version:}

Lea Lango, David Clarke. A metabolic switch is involved in life-style decisions in Photorhabdus luminescens. Molecular Microbiology, 2010, 77 (6), pp.1394. 10.1111/j.1365-2958.2010.07300.x . hal00560774

\section{HAL Id: hal-00560774 https://hal.science/hal-00560774}

Submitted on 30 Jan 2011

HAL is a multi-disciplinary open access archive for the deposit and dissemination of scientific research documents, whether they are published or not. The documents may come from teaching and research institutions in France or abroad, or from public or private research centers.
L'archive ouverte pluridisciplinaire HAL, est destinée au dépôt et à la diffusion de documents scientifiques de niveau recherche, publiés ou non, émanant des établissements d'enseignement et de recherche français ou étrangers, des laboratoires publics ou privés. 


\section{molecular microbiology}

\section{A metabolic switch is involved in life-style decisions in Photorhabdus luminescens}

\begin{tabular}{|r|l|}
\hline Journal: & Molecular Microbiology \\
\hline Manuscript ID: & MMI-2010-10131.R1 \\
\hline Manuscript Type: & Research Article \\
\hline $\begin{array}{r}\text { Date Submitted by the } \\
\text { Author: }\end{array}$ & 23-Jun-2010 \\
\hline Complete List of Authors: & $\begin{array}{l}\text { Lango, Lea; University College Cork, Department of Microbiology } \\
\text { Clarke, David; University College Cork, Ireland, Microbiology }\end{array}$ \\
\hline Key Words: & mdh, TCA cycle, secondary metabolism, mutualism \\
\hline \multicolumn{2}{|l}{} \\
\hline
\end{tabular}

\section{5 scholarONE" \\ Manuscript Central}


1 A metabolic switch is involved in life-style decisions in Photorhabdus

2 luminescens.

3 Lea Lango and David J. Clarke*

4 Department of Microbiology, University College Cork, IRELAND

5

$6 \quad$ : corresponding author

$7 \quad$ Tel: $+353(0) 214903624$

8 Email: $\underline{\text { david.clarke@ucc.ie }}$

9

10 Keywords: $m d h$, TCA cycle, secondary metabolism, mutualism 
1 Summary

2 Photorhabdus luminescens is a species of Gram negative bacteria that is pathogenic to

3 insects whilst also maintaining a mutualistic association with nematodes from the

4 family Heterorhabditis. P. luminescens elaborates an extensive secondary metabolism

5 during the post-exponential phase of growth that includes the production of an

6 antibiotic called 3-5-dihydroxy-4-isopropylstilbene (ST), an anthraquinone pigment

7 (AQ) and bioluminescence. In this study we identified a mutant that was unable to

8 produce ST, AQ and light. This mutation was found to be in the $m d h$ gene, encoding

9 malate dehydrogenase, a key enzyme in the TCA cycle. Interestingly the $m d h$ mutant

10 was unaffected in virulence but was unable to support nematode growth and

11 development in vivo or in vitro. This clearly establishes that secondary metabolism in

$12 P$. luminescens is required for the mutualistic interaction with the nematode.

13 Furthermore the construction of mutations in key genes in other central metabolic

14 pathways confirmed the critical role for the TCA cycle in both secondary metabolism

15 and mutualism, but not in virulence. Therefore we conclude that the TCA cycle is

16 required for the transition of $P$. luminescens from pathogen to mutualist implicating

17 the involvement of a metabolic switch in the regulation of life-style decisions in this 18 bacterium. 


\section{Introduction}

2 Photorhabdus is a genus of bioluminescent, Gram negative bacteria that is highly

3 virulent to insect larva whilst also maintaining a mutualistic relationship with soil-

4 dwelling nematodes from the family Heterorhabditis (Clarke, 2008, Waterfield et al.,

5 2009). Photorhabdus is normally found in gut of the infective juvenile (IJ) of the

6 heterorhabditid nematode (Ciche \& Ensign, 2003). The IJ is a specialized, non-

7 feeding stage of the nematode that is active for dispersal in the soil and infection of

8 new insect hosts (Ciche, 2007). Once inside the insect the IJ migrates to the

9 hemolymph where the bacterial symbionts are regurgitated. The bacteria replicate in

10 the nutrient-rich hemolymph reaching densities of $>10^{8}$ cfu/insect after $48-72 \mathrm{~h}$ at

11 which time the insect succumbs to septicemia. As a consequence of bacterial growth,

12 and due to the secretion of a range of hydrolytic enzymes, the internal organs of the

13 insect are converted into bacterial biomass and it is this biomass that is used by the

14 developing nematodes as food. The first step in nematode development is the

15 recovery of the IJ into a self-fertile adult hermaphrodite. This process is initially

16 stimulated by low molecular weight signals present in the insect hemolymph and,

17 subsequently, by a bacterial food signal that indicates the presence of a high density

18 of Photorhabdus (Joyce et al., 2008, Ciche \& Ensign, 2003). With the appropriate

19 conditions inside the insect cadaver the adult hermaphrodite nematode lays eggs that

20 hatch and develop through 4 juvenile molts (L1-L4) to give a new generation of adult

21 worms. As the nematode numbers increase (and food levels decrease) conditions

22 within the insect cadaver become sub-optimal and the juvenile nematodes are

23 stimulated to develop into the IJ, an alternative L3 stage. There can be $>100,000$ IJs in

24 a single insect cadaver and each IJ carries a population of approximately 100 colony 
1 forming units (cfu) of Photorhabdus arising from 1-2 bacterial cells that originally

2 colonize the IJ in a complex transmission process (Ciche et al., 2008).

4 Photorhabdus is both a pathogen and a mutualist and these different life-styles can be

5 temporally separated according to the growth phase of the bacteria (ffrench-Constant

6 et al., 2003). Photorhabdus have been shown to grow exponentially in the insect and

$7 \quad \mathrm{LT}_{50}$ values are tightly correlated with in vivo bacterial growth rates (Clarke \&

8 Dowds, 1995, Watson et al., 2005). On the other hand the nematodes develop and

9 reproduce in the insect cadaver only when Photorhabdus have reached a high cell

10 density and the bacteria have entered the post-exponential (stationary) phase of

11 growth (Hu \& Webster, 2000). Photorhabdus produce a range of activities during the

12 post-exponential phase of growth that appear to be important for the mutualistic

13 association with the nematode. These activities have been called symbiosis factors

14 and they include bioluminescence, an anthraquinone pigment (AQ), and a stilbene

15 based antibiotic called 3,5-dihydroxy-4-isopropylstilbene (ST) (Joyce et al., 2008,

16 Brachmann et al., 2007, Joyce \& Clarke, 2003). Therefore pathogenicity is associated

17 with exponentially growing bacteria whilst mutualism is associated with bacteria in

18 the post-exponential phase of growth.

20 In this study, we identify a mutant in P. luminescens TT01 that is unable to produce

$21 \mathrm{ST}, \mathrm{AQ}$ and bioluminescence. This mutation is in $m d h$, encoding the TCA cycle

22 enzyme malate dehydrogenase. We show that the $m d h$ mutant is not able to support

23 nematode growth and development in vivo or in vitro but is as virulent to insect larvae

24 as the wild-type. Therefore, although the $m d h$ mutant can grow in the insect, this

25 mutant cannot undergo the change from pathogen to mutualist implying that a 
1 metabolic switch, requiring a functional TCA cycle, controls this important bacterial

2 life-style transition.

3

\section{$4 \quad$ Results}

5 The $m d h$ gene is required for the production of ST, AQ and light. We recently

6 described the biochemical pathways required for the production of ST and AQ in $P$.

7 luminescens TT01 and, during the course of these studies, we undertook several Tn5-

8 based mutant screens to identify genes involved in these biosynthetic pathways (Joyce

9 et al., 2008, Brachmann et al., 2007, Williams et al., 2005). One mutant identified as

10 a non-producer of both ST and AQ during these studies was mapped to the $m d h$ gene,

11 encoding malate dehydrogenase (Mdh). P. luminescens is bioluminescent and light production is concomitant with ST and AQ biosynthesis. Further examination of the $m d h:$ Tn5 mutant suggested that this mutant was not capable of producing light (data not shown). To confirm these phenotypes we constructed a non-polar deletion mutation of the $m d h$ gene in TT01. As expected, the $\Delta m d h$ mutant was unable to produce ST, formed non-pigmented colonies on LB agar, and did not produce light (see Figure 1). All of these defects were complemented by the expression of $m d h$ in trans confirming that $m d h$ is required for the production of ST, AQ and bioluminescence in P. luminescens (see Figure 1).

1 The $\Delta m d h$ mutant is defective for growth in LB. It is well documented that the production of ST, AQ and light occurs during the post-exponential phase of $P$. luminescens growth in LB broth (Brachmann et al., 2007, Joyce \& Clarke, 2003, Daborn et al., 2001). Therefore, it was possible that the non-production of these phenotypes in the $\Delta m d h$ mutant was the result of a defect in growth. To test this we 
1 grew TT01 and the $\Delta m d h$ mutant in LB broth and, although both strains had a very

2 similar growth rate over the initial $9 \mathrm{~h}$ of incubation, it is clear that the $\Delta m d h$ mutant

3 stopped growing sooner, and at a lower $\mathrm{OD}_{600}$, than TT01 (see Figure $2 \mathrm{~A}$ ). This

4 cessation in growth of the $\Delta m d h$ mutant was very abrupt and occurred at a time that

5 corresponded to the entry into the post-exponential phase of the wild-type culture $(9 \mathrm{~h}$

6 post-inoculation). Importantly the growth characteristics of the $\Delta m d h$ mutant were

7 restored to wild-type by the expression of $m d h$ in trans confirming that the defect in

8 growth was due to the deletion of the $m d h$ gene. Viability counts showed that the

$9 \Delta m d h$ mutant stopped dividing at a cell density of $8.9 \times 10^{8} \mathrm{cfu} \mathrm{ml}^{-1}$ whilst the wild-

10 type entered the post-exponential phase at a cell density of $1.7 \times 10^{9} \mathrm{cfu} \mathrm{ml}^{-1}$,

11 achieving a final cell density of $2.7 \times 10^{9} \mathrm{cfu} \mathrm{ml}^{-1}$ after $24 \mathrm{~h}$ (see Figure 2B).

The $\Delta m d h$ mutant is defective in the assimilation of amino acids. During growth on peptone-based media such as LB bacteria need to be able to assimilate amino acids. Some amino acids require the TCA cycle for their effective catabolism. Mdh catalyses the interconversion of malate and oxaloacetate and is an important enzyme in the TCA cycle. Therefore the defect in growth observed with the $\Delta m d h$ mutant may be due to an inability to catabolize certain amino acids. To test this we measured the disappearance of amino acids from LB broth during the growth of TT01 and the $\Delta m d h$ mutant. Over the first $9 \mathrm{~h}$ (a period that corresponds to exponential growth (see Figure

21 1)) both the wild-type and the $\Delta m d h$ mutant have very similar utilization profiles with

22 the complete assimilation of serine and proline and partial assimilation of threonine,

23 alanine, glutamate, glycine, aspartate and arginine. In the wild-type cultures

24 assimilation of these amino acids continues until they are largely exhausted from the

25 LB after $24 \mathrm{~h}$ (note: cysteine, leucine, isoleucine, valine, methionine, lysine and 
1 phenylalanine levels were unchanged after $24 \mathrm{~h}$ indicating that these amino acids are

2 not effectively assimilated by Photorhabdus). In contrast, after $9 \mathrm{~h}$, the $\Delta m d h$ culture

3 exhibits very low rates of assimilation of threonine and alanine and no further

4 assimilation of the other amino acids (see Figure 3). Interestingly serine, alanine and

5 threonine are metabolized via pyruvate and assimilation does not require a functional

6 TCA cycle. On the other hand proline, glutamate, arginine and aspartate are

7 metabolized to TCA cycle intermediates and require a functional TCA cycle for

8 complete assimilation. Therefore the defect in growth observed with the $\Delta m d h$ mutant

9 in LB broth is likely due to the inability of this mutant to assimilate certain amino

10 acids as the result of a non-functional TCA cycle.

\section{The defect in the production of symbiosis factors is due to a defect in the TCA}

cycle. Mdh is required in the TCA cycle, the glyoxylate pathway and also, when cells

14 are growing on amino acids, gluconeogenesis. To determine what role of Mdh relates to the phenotypes reported here we constructed deletion mutants in key genes encoding proteins involved in these pathways: aceA (encoding isocitrate lyase (required for the glyoxylate pathway)), fumC (encoding fumarase $\mathrm{C}$ (required for the TCA cycle)) and $f b p$ (encoding fructose-1,6-biphosphatase (required for

19 gluconeogenesis). It is important to note that although E. coli has 3 genes predicted to encode fumarase activity ( $f u m A, f u m B$ and $f u m C$ ) the genome of TT01 is only predicted to have a single fumarase gene, fumC (Duchaud et al., 2003). These mutants were then tested for their ability to produce a range of activities associated with the post-exponential phase of growth in Photorhabdus (see Table 1). The $\triangle a c e A$ and $\Delta f b p$ mutants were essentially identical to the wild-type for all activities tested except for a

25 significantly reduced level of ST production in the $\Delta f b p$ mutant, suggesting that 
1 gluconeogenesis may have a specific role in ST production (see Table 1).

2 Interestingly the $\triangle$ fum $C$ mutant was non-pigmented and exhibited the same abrupt

3 cessation of growth shown with the $\Delta m d h$ mutant (see Table 1 and supplemental

4 Figure S1). Indeed phenotypic analyses suggest that the $\triangle f u m C$ mutation is even more

5 defective than the $\Delta m d h$ mutation in relation to the production of these activities (see

6 Table 1). Therefore we can conclude that the TCA cycle is required for the production

7 of a range of activities during the post-exponential phase of growth in Photorhabdus.

9 The acetate switch is not involved in the production of the symbiosis factors. The

10 assimilation of serine, alanine and threonine results in the excretion of acetate into the

11 growth medium. At some point during growth the excreted acetate can be taken up by

12 the growing cells and this change from acetate dissimilation to acetate assimilation is

13 called the acetate switch (Wolfe, 2005). The acetate switch has been shown to play an

14 important regulatory role in E. coli and other bacteria and acetate assimilation (and

15 therefore the acetate switch) requires a functional TCA cycle (Wolfe et al., 2003,

16 Wright et al., 2009). Therefore we wanted to determine if the acetate switch was

17 involved in the phenotype of the $\Delta m d h$ mutant. As expected both wild-type and $\Delta m d h$

18 mutants excreted acetate into the growth medium during the first $6 \mathrm{~h}$ of growth

19 (corresponding to the utilization of serine) (see Figure 4). Between 6-8 h post-

20 inoculation wild-type cells began to consume the acetate indicating that Photorhabdus

21 do exhibit an acetate switch during growth in LB broth. In contrast the $\Delta m d h$ mutant

22 does not undergo the acetate switch and these cells continue to excrete acetate

23 resulting in the accumulation of $10.3 \mathrm{mM}$ acetate in the growth medium after $25 \mathrm{~h}$

24 incubation (see Figure 4). As expected a similar profile for acetate production was

25 observed with the $\Delta f u m C$ mutant (see supplemental Figure S2). This data confirmed 
1 the non-functionality of the TCA cycle in the $\Delta m d h$ (and $\Delta f u m C$ ) mutant and

2 implicated the acetate switch as a potential player in the regulation of the post-

3 exponential phase phenotypes. To test this we constructed mutants in the ackA-pta

4 locus ( $\triangle a c k-p t a)$ and the acs gene in TT01 encoding the major acetate dissimilation

5 and assimilation pathways (Wolfe, 2005). We confirmed that the $\Delta a c k$-pta mutant did

6 not excrete acetate and the $\Delta a c s$ mutant could not assimilate acetate (see supplemental

7 Figure S2). Interestingly although the $\Delta$ acs mutant is expected not to be able to

8 assimilate acetate the levels of this organic acid remained constant after approx. $9 \mathrm{~h}$

9 suggesting that, unlike the $\Delta m d h$ and $\Delta f u m C$ mutants, the $\Delta a c s$ cells are no longer

10 metabolizing acetogenic amino acids. However phenotypic analysis of both the $\Delta a c k$ -

$11 p t a$ and $\Delta a c s$ mutants revealed that there were no difference between the mutants and

12 wild-type cells (see Table 1). In addition a $\Delta m d h \Delta a c k$-pta double mutant still

13 exhibited all of the phenotypes of the $\Delta m d h$ mutant (data not shown). Therefore the

14 assimilation and/or dissimilation of acetate is not involved in the phenotypes observed 15 with the $\Delta m d h$ mutant.

17 The TCA cycle is not required for pathogenicity. $P$. luminescens is a highly

18 virulent insect pathogen and bacterial growth within the insect has been shown to be

19 strongly correlated with virulence (as measured by $\mathrm{LT}_{50}$ ) (Watson et al., 2005, Clarke

$20 \&$ Dowds, 1995). Therefore to test for any affect on virulence we injected wild-type

21 and the mutant strains of TT01 into final instar larvae of Galleria mellonella, the

22 Greater Waxmoth. All of the mutants tested, with the exception of the $\Delta a c k-p t a$

23 mutant, had similar $\mathrm{LT}_{50}$ values when compared with the wild-type (see Table 2). The

$24 \Delta a c k$-pta mutant appeared to be attenuated in virulence with an extended $\mathrm{LT}_{50}$ of 59.1 
$1 \mathrm{~h}$ compared to $46 \mathrm{~h}$ for TT01 suggesting that acetate dissimilation may be important

2 for growth in the insect (see Table 2). Interestingly, similar to what we had observed

3 in vitro, the $\Delta m d h$ mutant only achieved a final cell density in the insect that was

4 approx. $50 \%$ of that achieved by the wild-type bacteria $\left(2.79 \times 10^{8} \mathrm{cfu} / \mathrm{insect}\right.$ for

5 TT01 compared to $1.49 \times 10^{8} \mathrm{cfu} /$ insect for $\Delta m d h$ ) (see Figure 5A). Moreover the

6 insect cadavers infected with the $\Delta m d h$ mutant were dark brown rather than the

7 characteristic bright orange pigmentation (indicative of AQ production) resulting

8 from infection with wild-type bacteria (see Figure 5B). The virulence, final cell

9 density within, and pigmentation of the insect cadaver infected with the $\Delta f u m C$

10 mutant was similar to the $\Delta m d h$ mutant (data not shown). On the other hand, the $\mathrm{LT}_{50}$

11 values for the $\triangle a c e A$ and $\Delta f b p$ mutants were indistinguishable from the wild-type

12 bacteria (see Table 1). Therefore this data shows that mutations in the TCA cycle,

13 whilst affecting the final bacterial cell density in the insect, do not affect virulence

14 against the insect host.

The TCA cycle is required for $\boldsymbol{P}$. luminecsens to be able to support nematode

17 growth and development. Photorhabdus also maintains a mutualistc association with

18 Heterorhabditis nematodes. Therefore we decided to examine the mutants constructed

19 in this study for a role in this symbiosis. Each of the strains was plated on lipid agar

20 and, after 3 days, the bacterial biomass was inoculated with 40 surface-sterilized IJs.

21 The recovery and growth of the nematode population within the bacterial biomass can

22 then be followed in situ. The first step in nematode growth and development is the

23 recovery of the IJ to an adult hermaphrodite (Joyce et al., 2008, Ciche, 2007).

24 Recovery was completely absent when IJs were inoculated onto either $\Delta m d h$ or

$25 \Delta f u m C$ mutant bacteria (data not shown). All of the other mutants tested ( $\triangle a c e A$, 
$1 \Delta f b p, \Delta a c k-p t a, \Delta a c s$ ) supported normal IJ recovery on lipid agar plates (data not

2 shown) and produced a new generation of IJs. These IJs (now carrying the bacteria on

3 which they were cultured) were used to infect insects and, after insect death, the

4 cadavers were placed in White traps in order to collect the IJs that will emerge after

5 nematode growth and development in vivo. Enumeration of these IJs facilitates a

6 quantitative assessment of how effective the mutants are at supporting nematode

7 growth and development in the insect. Therefore the IJs were collected and counted at

815,18 and 21 days post-infection and all of the mutants supported the development of

9 a high number of IJs in each insect $\left(>10^{5} \mathrm{IJ}\right.$ s/insect) confirming that the glyoxylate

10 pathway, acetate metabolism and gluconeogenesis are not essential for nematode

11 growth and development in vivo (see supplemental Figure S3). However it is

12 noteworthy that the cumulative IJ yield of each mutant was only approximately 50-

$1360 \%$ of the IJ yield from insects infected with TT01 suggesting that, although not

14 essential, these metabolic pathways might be important for the full exploitation of the

15 insect by the bacteria-nematode complex. Finally we also confirmed that the $\triangle a c e A$,

$16 \Delta f b p, \Delta a c k-p t a$ and $\Delta a c s$ mutants were competent for transmission to the new

17 generation of IJs (see Table 3). Therefore these genes (and their associated metabolic

18 pathways) are not required during the complex transmission process that involves

19 bacterial replication in both the hermaphrodite and the IJ (Ciche et al., 2008).

21 We have previously shown that ST production is required for IJ recovery during in

22 vitro symbiosis assays (Joyce et al., 2008). Therefore the absence of recovery with the

$23 \Delta m d h$ and $\Delta f u m C$ mutants might be simply explained by the inability of these cells to

24 produce this molecule (see Figure 1). In the insect, IJ recovery is independent of ST

25 and is stimulated by uncharacterized factors present in the insect hemolymph. 
1 Therefore to confirm that the defect observed during in vitro symbiosis with the $\Delta m d h$

2 mutants was not simply due to low levels of IJ recovery we co-infected insect larvae

3 with axenic IJs and either TT01 or $\Delta m d h$ bacteria and 7 days later the insect cadavers

4 were dissected to observe the nematode population. As expected there was a

5 significant mixed-stage nematode population present within insects killed by the wild-

6 type bacteria (see Figure 6). Moreover the bacteria were present as a structured,

7 pigmented mass that was difficult to disperse. We also observed nematodes grazing

8 throughout this structured mass. On the other hand we could only detect a few

9 nematodes present in insects infected with the $\Delta m d h$ mutant (see Figure 6). These

10 nematodes were larger than the IJ, indicating that recovery had been initiated, but

11 were invariably dead suggesting that conditions within the cadaver were not

12 permissive for nematode growth and development. Therefore we can conclude that

13 Photorhabdus require a functional TCA cycle in order to be able to support nematode

14 growth and development in the insect. Interestingly the appearance of the $\Delta m d h$

15 mutant biomass within the cadaver was very different from that observed with wild-

16 type bacteria i.e. it was neither pigmented nor structured and dispersed very easily in

17 the buffer. This suggests that the TCA cycle is also important for driving significant

18 morphological developments within the bacterial population that may be important for

19 the mutualistic interaction with the nematode.

\section{Discussion}

22 In this study we have shown that the TCA cycle is required in order that $P$.

23 luminescens can change its lifestyle from pathogen to mutualist. We have shown that

24 this lifestyle switch is concomitant with the transition from exponential to post-

25 exponential growth and, moreover, that the TCA cycle is required for the production 
1 of symbiosis factors during the post-exponential phase of bacterial growth. These

2 symbiosis factors include, but are not limited to, light, AQ and ST. The coordinated

3 production of these symbiosis factors during post-exponential growth (notably when

4 bacterial cell densities are high) is typical of secondary metabolism but is also

5 reminiscent of a phenomenon called group behavior. The molecular mechanisms

6 controlling group behavior in model species such as Pseudomonas aeruginosa and

7 have been well characterized and it is now established that this behavior involves

8 complex regulatory networks that are controlled by signaling molecules such as

9 acylhomoserine lactones (AHL) and c-di-GMP (Schirmer \& Jenal, 2009, Williams \&

10 Camara, 2009, Hengge, 2009, Romling et al., 2005). Remarkably analysis of the

11 genome sequence of $P$. luminescens TT01 does not identify any typical AHL

12 synthases and Photorhabdus has not been reported to have any AHL-based quorum

13 sensing networks (Duchaud et al., 2003, Derzelle et al., 2002). Moreover

14 Photorhabdus does not encode any gene with a predicted role in the synthesis,

15 turnover or sensing of the c-di-GMP molecule (Duchaud et al., 2003, Galperin, 2004).

16 Therefore, in the absence of these well characterized signaling molecules it was

17 possible that a metabolic switch (perhaps associated with the transition from

18 exponential to post-exponential growth) might be involved in coordinating the

19 expression of the symbiosis factors. In this study we have identified the TCA cycle as

20 part of the metabolic switch that controls life-style decisions in Photorhabdus and we

21 have thus established a link between central metabolism and group behavior in this

22 bacterium.

24 Photorhabdus have been shown to grow exponentially in the insect and the bacterial

25 growth rate is closely correlated with $\mathrm{LT}_{50}$ values (Watson et al., 2005, Clarke \& 
1 Dowds, 1995). Therefore mutants that are affected in their in vivo growth rate are

2 attenuated in virulence as they have extended $\mathrm{LT}_{50}$ values compared to the wild-type

3 (Watson et al., 2005). All of the mutants analyzed in this study, with the exception of

4 the $\Delta a c k$-pta mutant, were unaffected in their $\mathrm{LT}_{50}$ suggesting that the TCA cycle,

5 gluconeogenesis and the glyoxylate pathway are not required for in vivo growth and,

6 therefore, pathogenicity. The reason for the attenuation observed with the $\Delta a c k-p t a$

7 mutant may be related to the accumulation of acetyl-CoA and pyruvate that would be

8 expected to occur in this mutant. We also have preliminary evidence that a mutation

9 in $p f k A$, encoding 6-phosphofructokinase (an enzyme specific for glycolysis) is

10 unaffected in its $\mathrm{LT}_{50}$ suggesting that glycolysis is not required for growth in the

11 insect (our unpublished data). Therefore it appears that abrogation of any single

12 metabolic pathway has little or no affect on the in vivo growth rate of TT01. The

13 insect hemolymph is a rich source of nutrients including amino acids, such as serine,

14 and glycolytic sugars. Therefore it appears that $P$. luminescens has a robust

15 metabolism during infection, a phenomenon that has also been observed in

16 Salmonella (Becker et al., 2006). As a result it is likely that Photorhabdus expresses

17 redundant metabolic pathways during the early stages of infection (corresponding to

18 exponential growth) in order to exploit all of the different nutrients available in the

19 insect. However, we did observe that, similar to what was observed during growth in

20 LB broth, the $\Delta m d h$ (and $\Delta f u m C$ ) mutant did not reach the same cell densities inside

21 the insect cadaver as the wild-type (see Figure 5). Moreover, during post-exponential

22 growth on LB agar the $\Delta m d h$ (and $\Delta f u m C$ ) mutant failed to produce significant

23 amounts of light, AQ or ST (see Figure 1). Similarly we observed that the insect

24 cadaver infected with $\Delta m d h$ (or $\Delta f u m C$ ) mutant cells failed to pigment suggesting that

25 the symbiosis factors are not being produced in these cadavers (see Figure 5). 
1 Therefore it is clear that the TCA cycle plays a key role in controlling post-

2 exponential growth and secondary metabolism in P. luminescens both in vivo and in

3 vitro.

5 Our data shows that, in LB broth, Photorhabdus achieve exponential growth through

6 the assimilation of acetogenic amino acids, primarily serine. Moreover exponential

7 growth in LB broth appears to be independent of the TCA cycle, gluconeogenesis and

8 the glyoxylate pathway. Although the TCA cycle is not required for the exponential

9 growth of $P$. luminescens in vivo or in vitro it is clear that this metabolic pathway is

10 important during post-exponential growth. Mutations in either $m d h$ or fumC resulted

11 in an abrupt and early cessation in growth in vitro and in vivo. In E. coli a similar in

12 vitro growth phenotype was reported in cells carrying a mutation in the nuo locus,

13 encoding NADH dehydrogenase I (Pruss et al., 1994). It was proposed that the growth

14 defect in the E. coli nuo mutants was due to the accumulation of NADH in the cell

15 and the subsequent inhibition of key TCA cycle enzymes such as Mdh. Therefore the

16 requirement for an active TCA cycle during post-exponential growth is not restricted

17 to Photorhabdus. Indeed the TCA cycle has been shown to be required for the post-

18 exponential production of capsule in Staphylococcus aureus and P. aeruginosa

19 (Somerville et al., 2002, Sadykov et al., 2010, Hassett et al., 1997). Nonetheless it is

20 clear that, in Photorhabdus, the TCA cycle is linked to an elaborate post-exponential

21 (i.e. secondary) metabolism that is required for the interaction between the bacterium 22 and its nematode host.

24 Secondary metabolism has been best studied in Streptomyces, an important source of 25 bioactive compounds and a metabolic switch has been implicated in the transition 
1 from primary to secondary metabolism in this bacterium (Nieselt et al., 2010). This

2 switch is controlled by environmental conditions (e.g. nutritional status) and is linked

3 to complex changes in gene expression mediated by master regulators such as PhoP

4 and AfsR (Martin \& Liras, 2010, Sola-Landa et al., 2003, Santos-Beneit et al., 2009).

5 In $P$. luminescens the UvrY response regulator has been identified as a positive

6 regulator of AQ, ST and light production (Krin et al., 2008). Therefore a mutation in

7 the $u v r Y$ gene in $P$. luminescens resulted in lower expression levels of the ant operon

8 (responsible for AQ production), stlA (encoding phenylalanine ammonia lyase,

9 catalyzing the first step in ST biosynthesis) and the luxCDABE operon (responsible

10 for bioluminescence) (Krin et al., 2008). Interestingly secondary metabolism in

11 Pseudomonas fluorescens $\mathrm{CHAO}$, an important antagonist of phyopathogenic fungi

12 found in the rhizosphere of corn, is also controlled by the BarA/UvrY homologues,

13 GacS/GacA (Hassan et al., 2010, Kay et al., 2005, Lapouge et al., 2008). Moreover

14 mutations in genes encoding key TCA cycle enzymes (i.e. $p y c A B$ encoding pyruvate

15 decarboxylase and fumA, encoding fumarase A) have been shown to affect the activity

16 of the GacS/GacA pathway in P. fluorescens CHAO suggesting a link between the

17 TCA cycle and secondary metabolism (Takeuchi et al., 2009). In P. fluorescens these

18 mutations were shown to affect GacS/GacA activity by altering the levels of TCA

19 cycle intermediates such as $\alpha$-ketoglutarate, succinate and fumarate (Takeuchi et al.,

20 2009) and it is tempting to speculate that, in a similar way, the BarA/UvrY pathway in

21 Photorhabdus may be responding to changes in the pool of TCA cycle intermediates.

22 However the TCA cycle is also required for the production of reducing equivalents

23 (i.e. $\mathrm{NADH}$ ) that can be converted to energy via the electron transport chain. In a

24 recent report it was shown that increasing the levels of proline enhances the

25 production of ST and AQ by $P$. luminescens in both rich media and filtered insect 
1 hemolymph (Crawford et al., 2010). It was proposed that proline, an amino acid that

2 is present at relatively high levels in insect hemolymph, acts as a signal for the

3 bacterium to indicate that it is in the insect host (Crawford et al., 2010). Proline

4 assimilation requires proline dehydrogenase (encoded by putA) and results in the

5 generation of both glutamate and NADH. It was shown that the proline-dependent

6 increase in AQ production was linked to an increase in the production of reducing

7 equivalents suggesting that the production of NADH may be an important

8 requirement for secondary metabolism in Photorhabdus (Crawford et al., 2010).

9 Interestingly, Mdh activity generates NADH when converting malate to oxaloacetate

10 and the $\Delta m d h$ and $\Delta f u m C$ mutants do not appear to reduce the tetrazolium salt present

11 in the NBT agar plates suggesting that these strains are compromised in their ability to

12 generate reducing equivalents (see Table 1). However, Table 1 also shows that the

$13 \Delta f u m C$ mutant exhibits a more extreme phenotype than the $\Delta m d h$ mutant and, as

14 fumarase activity does not generate NADH, this would not be expected to be the case

15 if the sole role for the TCA cycle in secondary metabolism in Photorhabdus was the

16 generation of reducing equivalents. Therefore the exact nature of the interface

17 between primary metabolism, secondary metabolism and mutualism in Photorhabdus

18 remains to be determined.

19

20 Experimental procedures

21 Bacterial strains and growth conditions.

22 A spontaneous rifampicin-resistant mutant of Photorhabdus luminescens subsp

23 laumondii TT01 was used as the wild-type in all experiments (Bennett \& Clarke,

24 2005). Bacteria were cultured in LB broth or on LB agar (LB broth $+1.5 \%(w / v)$

25 agar) at $30^{\circ} \mathrm{C}$. All LB agar plates were supplemented with $0.1 \%(w / v)$ pyruvate, 
1 unless otherwise stated. When required antibiotics were added at the following

2 concentrations: ampicillin (Amp): $100 \mu \mathrm{g} \mathrm{ml}^{-1}$; chlormaphenicol (Cm): $20 \mu \mathrm{g} \mathrm{ml}^{-1}$;

3 kanamycin (Km): $30 \mu \mathrm{g} \mathrm{ml}^{-1}$; rifampicin (Rif): $100 \mu \mathrm{g} \mathrm{ml}^{-1}$.

4

5

\section{Construction of deletion mutants}

The $m d h:: \operatorname{Tn} 5$ insertion mutant was originally identified during a previously described screen for mutants that were unable to produce the ST antibiotic (Williams et al., 2005). Specific deletion mutants were constructed using a 3-step PCR protocol developed in our laboratory (Joyce et al., 2008, Brachmann et al., 2007). Deletion mutants are constructed so that the predicted ORF is completely deleted leaving only the start and stop codons to minimize polarity. Briefly primer pairs $\mathrm{A}+\mathrm{B}$ and $\mathrm{C}+\mathrm{D}$ (see supplemental Table S1) were used to amplify approx. 500bp of the upstream and downstream flanking DNA the gene to be deleted. These amplicons were designed to have complementary ends (i.e. the 5'end of primers $\mathrm{B}$ and $\mathrm{C}$ for each gene are complimentary) so that, when mixed, the PCR fragments formed a full-length chimeric molecule that could be amplified using the appropriate primers (i.e. primers A and D). This full-length amplicon was cloned into the mobiliseable suicide vector pDS132 and the plasmid was conjugated from E. coli S17-1 ( $\lambda$ pir) into $P$. luminescens TT01 as previously described (Easom \& Clarke, 2008). After overnight incubation of the conjugation mix on $\mathrm{LB}$ agar at $30^{\circ} \mathrm{C}$ exconjugants were selected by plating the resuspended cells on LB agar plates supplemented with Rif and Cm. The pDS132 plasmid contains the $s a c B$ gene and, therefore, a second recombination event was selected for by picking a colony into LB broth and culturing the cells at $30^{\circ} \mathrm{C}$ without any antibiotic selection. After 18-24 h serial dilutions of the culture were prepared and $100 \mu \mathrm{l}$ of each dilution was spread onto LB agar supplemented with 
$10.2 \%(w / v)$ sucrose. Suc ${ }^{\mathrm{R}}$ mutants were replica plated on agar plates containing $\mathrm{Cm}$

2 and $\mathrm{Suc}^{\mathrm{R}} \mathrm{Cm}^{\mathrm{S}}$ colonies were screened for the presence of the deletion mutation by

3 colony PCR and the primers designated F and R for each gene (see supplemental

4 Table S1).

5

6 Cloning of mdh into pTRC99a

$7 \quad$ The $m d h$ gene was amplified from $P$. luminescens TT01 chromosomal DNA using

8 PCR and the primers JW132 [5'-ttattccatggaagttgcagttctcggtgcagc-3'] and JW133 [5'-

9 tatttctagattagttattaataaatttttcgcctaattc-3']. The amplicon was digested with NcoI and

$10 X b a \mathrm{I}$ and ligated into pTRC99a digested with the same restriction enzymes resulting

11 in the plasmid, pBMM935. The integrity and accuracy of the insert was confirmed by

12 DNA sequencing. The preparation of electrocompetent cells of $P$. luminescens TT01

13 and mutant derivatives was carried out as previously described (Bennett \& Clarke, 14 2005).

Phenotypic tests

17 For all phenotypic tests cells were cultured overnight in LB broth at $30^{\circ} \mathrm{C}$, the $\mathrm{OD}_{600}$

18 of the culture was adjusted to 1 and $5 \mu$ of each cell suspension was spotted onto the

19 surface of a LB agar plate and incubated for 3 days at $30^{\circ} \mathrm{C}$. AQ production was

20 qualitatively assessed on the basis of the level of colony pigmentation compared to

21 wild-type colonies. These colonies were also assessed for light production using an In

22 Vitro Imaging System (IVIS-100, Xenogen Alameda, Ca.). ST production was

23 assessed using a Micrococcus overlay assay. Briefly colonies were grown on LB agar

24 for 3 days at $30^{\circ} \mathrm{C}$ before being overlayed with soft agar (LB broth supplemented with

$250.3 \%(\mathrm{w} / \mathrm{v})$ agar) containing Micrococcus luteus. The level of ST production was 
1 determined by measuring the size of the halo surrounding each colony (Williams et

2 al., 2005). Siderophore production was measured using LB agar supplemented with

3 CAS (Watson et al., 2005). NBT agar is nutrient agar supplemented with $25 \mu \mathrm{g} \mathrm{ml}^{-1}$

4 bromothymol blue and $30 \mu \mathrm{g} \mathrm{ml}^{-1}$ 2,3,5-tetrazolium salt. Lipase production was

5 measured using nutrient agar supplemented with Tween 80 and $\mathrm{CaCl}_{2}$. Protease

6 production was measured using skimmed milk agar. Motility was determined using

7 swim agar (LB broth supplemented with 0.3\% (w/v) agar) (Easom \& Clarke, 2008).

8 Catalase production was detected using the fizz test whereby cells from an overnight

9 culture were mixed with $\mathrm{H}_{2} \mathrm{O}_{2}$ and the formation of bubbles is indicative of catalase

10 production (Joyce \& Clarke, 2003).

Amino acid analysis and determination of acetate levels

13 Single colonies were picked into $5 \mathrm{ml} \mathrm{LB}$ broth and grown overnight at $30^{\circ} \mathrm{C}$. The

14 overnight culture was then inoculated into $50 \mathrm{ml}$ of LB broth to achieve a starting

$15 \mathrm{OD}_{600}$ of 0.05 and cultures were grown, shaking at $200 \mathrm{rpm}$, in $250 \mathrm{ml}$ flasks at $30^{\circ} \mathrm{C}$.

16 After 3, 6, 9 and $24 \mathrm{~h}$ a $5 \mathrm{ml}$ aliquot was taken from each flask, the cells were

17 removed by centrifugation and the supernatants were filter-sterilised, through a 0.2

$18 \mu \mathrm{m}$ filter, and stored at $-20^{\circ} \mathrm{C}$ until required. For amino acid analysis, samples were

19 deproteinised by mixing equal volumes of $24 \%$ (w/v) trichloroacetic acid (TCA) and

20 sample. The mixtures were allowed to stand for 10 minutes before centrifuging at

21 14,400 x g (Microcentaur, MSE, UK) for $10 \mathrm{~min}$. Supernatants were removed and

22 diluted with $0.2 \mathrm{M}$ sodium citrate buffer, $\mathrm{pH} 2.2$ to give approximately $250 \mathrm{nmol}$ of

23 each amino acid residue. Samples were then diluted 1 in 2 with the internal standard,

24 norleucine, to give a final concentration of $125 \mathrm{~nm} / \mathrm{ml}$. Amino acids were quantified

25 using a Jeol JLC-500/V amino acid analyser (Jeol (UK) Ltd., Garden city, Herts, UK) 
1 fitted with a Jeol $\mathrm{Na}^{+}$high performance cation exchange column. Acetate levels were

2 determined by high performance liquid chromatography (HPLC) using an Agilent

$31200 \mathrm{HPLC}$ system with a refractive index detector. A REZEX $8 \mu 8 \% \mathrm{H}$, Organic

4 Acid Column $300 \times 7.8 \mathrm{mM}$ (Phenomenex, USA) was used with $0.01 \mathrm{~N} \mathrm{H}_{2} \mathrm{SO}_{4}$ as the

5 elution fluid, at a flow rate of $0.6 \mathrm{ml} / \mathrm{min}$. The temperature of the column was

6 maintained at $65^{\circ} \mathrm{C}$. Acetate peaks were identified by comparison of their retention

7 times with those of pure compounds and concentrations were determined from

8 standards of known concentrations.

9

10 Pathogenicity assay

11 The pathogenicity of $P$. luminescens strains was assessed using Galleria mellonella

12 larvae, purchased from Livefood (UK), as the model insect host. Briefly, overnight

13 cultures of $P$. luminescens TT01 and mutant derivatives were washed 3 times in $1 \mathrm{x}$

14 PBS before the $\mathrm{OD}_{600}$ was adjusted to 1.0 (equivalent to $4 \times 10^{8} \mathrm{cfu} \mathrm{ml}^{-1}$ ). The culture

15 was then diluted to a cell density of $2 \times 10^{4} \mathrm{cfu} \mathrm{ml}^{-1}$ and $10 \mu \mathrm{l}$ (equivalent to $200 \mathrm{cfu}$ )

16 was injected into the hemolymph of a G. mellonella larva using a Hamilton syringe

17 and a BD Microlance ${ }^{\mathrm{TM}} 330 \mathrm{G}$ x 1/2" needle. The injected insect larvae were placed

18 into a Petri dish containing some Whatman paper and incubated at $25 \mathrm{C}$ and, at the

19 appropriate times, the insects were checked for signs of life by gentle prodding with a

20 sterile yellow tip.

21

22 In vitro symbiosis assay

23 In vitro symbiosis assays were carried out as previously described (Easom \& Clarke,

24 2008). Briefly an overnight culture of the appropriate bacteria was diluted to an $\mathrm{OD}_{600}$

$25=1$ and $50 \mu \mathrm{l}$ was spread, in a $\mathrm{Z}$ pattern, onto the surface of a lipid agar plate (/L: $10 \mathrm{~g}$ 
1 corn syrup, $5 \mathrm{~g}$ yeast extract, $25 \mathrm{~g}$ nutrient agar, $5 \mathrm{ml}$ cod liver oil, $2 \mathrm{~g} \mathrm{MgCl}_{2} \cdot 6 \mathrm{H}_{2} \mathrm{O}$ )

2 using an inoculating loop. The plates were incubated at $30^{\circ} \mathrm{C}$ for 3 days before 50

3 surface sterilised IJ nematodes were added to the bacterial biomass. Nematodes were

4 surface-sterilised by washing in a solution $(0.4 \%(\mathrm{w} / \mathrm{v}))$ of hyamine (Sigma).

$5 \quad$ Nematode recovery was assessed 7 days later by counting the number of

6 hermaphrodites on the lipid agar plate. After 21 days, the new generation of IJs was

7 collected and the number of IJs present (i.e. the IJ yield) was determined. The number

8 of bacteria present levels in the IJ (i.e. colonization levels) was determined by

9 crushing individual, surface-sterilised IJ nematodes in $100 \mu 11 \times$ PBS using a hand-

10 held homogeniser. At least $10 \mathrm{IJs}$ were crushed for each mutant strain and the bacteria

11 were enumerated by plating the homogenate onto LB (Rif) agar.

Co-infection symbiosis assays

14 To determine the ability of mutant bacteria to support nematode growth and

15 development in vivo we co-infected insect larvae with the bacteria being tested and

16 axenic IJ nematodes. Axenic nematodes were produced by growing $H$. bacteriophora

17 TT01 nematodes on a bacterial lawn of $P$. temperata K122. Under these conditions

18 the nematodes grow well but the $P$. temperata $\mathrm{K} 122$ bacteria are unable to colonize

19 the H. bacteriophora IJ (our unpublished data). Axenicity was confirmed by a)

20 crushing 1000 surface-sterilized IJs and plating the homogenate on LB agar and b)

21 allowing the IJs to infect insects to confirm that there was no insect death. To

22 establish co-infections insects were first injected with the appropriate bacteria using

23 the same procedure outlined for pathogenicity assays. The injected insects were then

24 placed in a Petri dish containing Whatman filter paper that had been previously

25 wetted with $1 \mathrm{ml}$ PBS containing 1000 axenic IJs. The insects were left on the filter 
1 paper for 3 days at $25^{\circ} \mathrm{C}$ (until insect death) and then transferred to fresh Petri dishes.

2 After a further 4 days incubation at $25^{\circ} \mathrm{C}$ the insect cadavers were surface sterilized

3 by dipping the cadaver in ethanol before removing the ethanol by flaming. The

4 cadavers were then dissected by placing in a Petri dish containing $10 \mathrm{ml}$ sterile $1 \mathrm{x}$

$5 \quad$ PBS and disrupting the cuticle using a sterile scalpel blade.

7 Acknowledgments

8 The authors would like to thank all members of the laboratory for their help and

9 suggestions. In particular we would like to thank Marie Thompson and Harriet Taylor

10 (University of Bath) for their preliminary work. The authors would also like to thank

11 Alan Wolfe (Loyola University) and Susan Joyce (UCC) for advice on technical 12 aspects of this work and (Teagasc) for amino acid analysis. This work was supported 13 by Science Foundation Ireland with an award through the Research Frontiers 14 Programme (RFP/07/GENF546).

Figure Legends

17 Figure 1. The $\Delta m d h$ mutant does not produce AQ, ST or light. TT01 and $\Delta m d h$ cells 18 carrying either pTRC99a (vector) or pBMM953 ( $\mathrm{pmdh}$ ) were cultured overnight at $1930^{\circ} \mathrm{C}$. The $\mathrm{OD}_{600}$ of the culture was adjusted to 1.0 and $5 \mu \mathrm{l}$ of each cell suspension 20 was spotted onto the surface of a LB agar plate and incubated for 3 days at $30^{\circ} \mathrm{C}$ for 21 AQ production (as indicated by level of pigmentation), ST production and 22 bioluminescence.

24 Figure 2. Growth of the $\Delta m d h$ mutant in LB broth. A) Overnight cultures of TT01 25 carrying pTRC99a (filled circle) and $\Delta m d h$ carrying pTRC99a (open circle) or 
1 pBMM953 (open squares) were inoculated into fresh LB broth (+Amp) supplemented

2 with $0.1 \mathrm{mM}$ IPTG and incubated, with shaking at $200 \mathrm{rpm}$, at $30^{\circ} \mathrm{C}$. Samples were

3 taken at regular time intervals to measure $\mathrm{OD}_{600}$ and the graph shown is a

4 representative curve. B) Overnight cultures of TT01 (filled circle) and $\Delta m d h$ (open

5 circle) were inoculated into fresh LB broth and samples were withdrawn at regular

6 intervals and spread onto LB agar to enumerate colony forming units (cfu). The

7 results shown are the mean of 3 experiments and error bars represent the standard

8 deviation.

9

10 Figure 3. Assimilation of amino acids during growth in LB. TT01 and $\Delta m d h$ cells

11 were grown overnight and inoculated into $50 \mathrm{ml}$ fresh LB broth and incubated, with

12 shaking, at $30^{\circ} \mathrm{C}$. Aliquots were taken at regular intervals, the cells were removed by

13 centrifugation and the supernatant was analyzed for amino acid levels as described in

14 Experimental procedures. The results shown are the mean values from 3 replicates

15 inoculated with independent overnight cultures and cultured in the same batch of LB

16 broth. Standard deviations ( $<1 \%$ in all cases) are not shown for clarity.

18 Figure 4. Determination of acetate levels during growth in LB. TT01 cells (dark bars)

19 and $\Delta m d h$ cells (light bars) were cultured as described in the legend for Figure 3.

20 Samples were withdrawn at regular intervals and supernatants were analyzed for

21 acetate levels using HPLC. Experiments were carried out three times using

22 independent cultures and the mean acetate levels are shown with the standard error. A

23 representative growth curve for TT01 (filled circle) and $\Delta m d h$ (open circle) is also

24 shown for reference.

25 
1 Figure 5. In vivo growth of TT01 and $\Delta m d h$. A) Insects were injected with $200 \mathrm{cfu}$ of

2 each strain from an overnight culture. The infected larvae were incubated at $30^{\circ} \mathrm{C}$ and

3 the density of bacteria within the cadavers after $72 \mathrm{~h}$ was determined by

4 homogenizing the cadaver and enumerating the bacteria present by spreading the

5 homogenate on LB agar. The results shown represent the mean cfu/insect calculated

6 from 3 cadavers and the error bars represent the standard deviation. B) The difference

7 in the level of pigmentation observed in insect cadavers $72 \mathrm{~h}$ after being infected with

8 either TT01 or $\Delta m d h$ bacteria.

9

10 Figure 6. Nematode growth and development in the insect. G. mellonella larvae were

11 co-infected with axenic $H$. bacteriophora IJ nematodes and either TT01 or $\Delta m d h$ (as

12 described in Experimental procedures). The cadavers were dissected 7 days after

13 infection and examined for the presence of nematodes. Nematodes are abundant in the

14 cadaver infected with TT01 bacteria whilst only 1 nematode (indicated with black

15 arrow) was seen within the cadaver infected with $\Delta m d h$ bacteria. In addition, within

16 insects infected with TT01, the bacterial biomass was clearly evident as a structured,

17 pigmented mass (indicated with white arrow). On the other hand this mass was not

18 observed in insects infected with $\Delta m d h$ bacteria.

19 
2 Table 1. Phenotypes of mutants used in this study.

3

\begin{tabular}{|c|c|c|c|c|c|c|c|}
\hline & TT01 & $\Delta m d h$ & $\Delta f u m C$ & $\triangle a c e A$ & $\Delta f b p$ & $\Delta a c s$ & $\Delta a c k-p t a$ \\
\hline $\mathrm{OD}_{600}$ & 6.5 & 2.4 & 1.7 & 6.6 & 7.3 & 6.6 & 6.5 \\
\hline AQ & +++ & - & - & +++ & ++ & +++ & ++ \\
\hline ST & +++ & - & - & +++ & $-/+$ & +++ & +++ \\
\hline bioluminescence & +++ & - & - & +++ & +++ & +++ & ++++ \\
\hline siderophore & +++ & - & $-^{\mathrm{a}}$ & +++ & ++ & +++ & +++ \\
\hline Colour on NBT agar & red & yellow & yellow & red & red & red & red \\
\hline Lipase & +++ & ++ & - & +++ & +++ & +++ & +++ \\
\hline Protease & +++ & +++ & $-{ }^{\mathrm{a}}$ & +++ & +++ & +++ & +++ \\
\hline Catalase & +++ & +++ & - & +++ & +++ & +++ & n.d. \\
\hline Motility & +++ & +++ & ++++ & +++ & +++ & +++ & +++ \\
\hline & & & & & & & \\
\hline${ }^{\mathrm{a}}$ : poor growth & & & & & & & \\
\hline n.d.: not determined & & & & & & & \\
\hline & & & & & & & \\
\hline
\end{tabular}


1 Table 2. $\mathrm{LT}_{50}$ values for TT01 and mutant derivatives.

2

\begin{tabular}{|c|c|}
\hline Strain & $\mathrm{LT}_{50}(\mathrm{~h})^{\mathrm{a}}$ \\
\hline TT01 & $46 \pm 2.0$ \\
\hline$\Delta m d h$ & $48.7 \pm 0.9$ \\
\hline$\Delta f u m C$ & $48.8 \pm 2.3$ \\
\hline$\triangle a c e A$ & $43.5 \pm 0.6$ \\
\hline$\Delta f b p$ & $48.6 \pm 2.4$ \\
\hline$\Delta a c k-p t a$ & $59.1 \pm 0.64^{b}$ \\
\hline$\Delta a c s$ & $42.2 \pm 1.13$ \\
\hline
\end{tabular}

3

$4 \quad$ a: values shown are the mean \pm standard deviation resulting from the direct injection

5 of 100 cfu of each mutant into 10 insect larvae $(n \geq 3)$.

$6{ }^{\mathrm{b}}$ : the $\mathrm{LT}_{50}$ values was calculated from only 2 experiments as only 4 insects (out of 10)

7 died within $80 \mathrm{~h}$ in the third experiment.

8 
1 Table 3. Colonization levels of TT01 and mutant derivatives in IJ nematodes.

2

\begin{tabular}{ll} 
Strain & cfu/IJ ${ }^{\mathrm{a}}$ \\
\hline TT01 & $88(26-114)$ \\
$\Delta m d h$ & $-{ }^{\mathrm{b}}$ \\
$\Delta f u m C$ & $-{ }^{\mathrm{b}}$ \\
$\Delta a c e A$ & $53(2-128)$ \\
$\Delta f b p$ & $63(26-256)$ \\
$\Delta a c k-p t a$ & $47(14-90)$ \\
$\Delta a c s$ & $56(10-192)$
\end{tabular}

3

$4 \quad$ a: values shown are the median (range is in parenthesis) of cfu enumerated from 10

5 individual IJs for each strain (with the exception of TT01 $(n=5))$.

6 b: colonization levels could not be calculated as nematodes did not grow on these

7 mutants

8 


\section{Bibliography}

2 Becker, D., Selbach, M., Rollenhagen, C., Ballmaier, M., Meyer, T. F., Mann, M. and

3 Buann, D. (2006) Robust Salmonella metabolism limits possibilities for new

$4 \quad$ antimicrobials. Nature 440: 303-307.

5 Bennett, H. P. and Clarke, D. J. (2005) The pbgPE operon in Photorhabdus

$6 \quad$ luminescens is required for pathogenicity and symbiosis. J Bacteriol 187: 77784.

8 Brachmann, A. O., Joyce, S. A., Jenke-Kodoma, H., Schwar, G., Clarke, D. J. and Bode,

9 H. B. (2007) A type II polyketide synthase is responsible for anthraquinone

10 biosynthesis in Photorhabdus luminescens. Chembiochem 8: 1721-1728.

11 Ciche, T. (2007) The biology and genome of Heterorhabditis bacteriophora.

12 WormBook: 1-9.

13 Ciche, T. A. and Ensign, J. C. (2003) For the insect pathogen Photorhabdus

14 luminescens, which end of a nematode is out? Appl Environ Microbiol 69: 1890$15 \quad 1897$.

16 Ciche, T. A., Kim, K., Kaufmann-Daszczuk, B., Nguyen, K. C. Q. and Hall, D. H.

17 (2008) Cell invasion and matricide during Photorhabdus luminescens

18 transmission by Heterorhabditis bacteriophora nematodes. Appl Environ

$19 \quad$ Microbiol 74: 2275-2287.

20 Clarke, D. J. (2008) Photorhabdus: a model for the analysis of pathogenicity and 21 mutualism. Cell Microbiol 10: 2159-2167.

22 Clarke, D. J. and Dowds, B. C. A. (1995) Virulence mechanisms of Photorhabdus sp

23 strain K122 toward Wax Moth larvae. J Invert Pathol 66: 149-155.

24 Crawford, J. M., Kontnik, R. and Clardy, J. (2010) Regulating alternative lifestyles 25 in entomopathogenic bacteria. Curr Biol 20: 69-74. 
1 Daborn, P. J., Waterfield, N., Blight, M. A. and Ffrench-Constant, R. H. (2001)

2 Measuring virulence factor expression by the pathogenic bacterium

3 Photorhabdus luminescens in culture and during insect infection. J Bacteriol

$4 \quad$ 183: $5834-5839$.

5 Derzelle, S., Duchaud, E., Kunst, F., Danchin, A. and Bertin, P. (2002)

6 Identification, characterization, and regulation of a cluster of genes involved

7 in carbapenem biosynthesis in Photorhabdus luminescens. Appl Environ

$8 \quad$ Microbiol 68: 3780-3789.

9 Duchaud, E., Rusniok, C., Frangeul, L., Buchrieser, C., Givaudan, A., Taourit, S., et

10 al. (2003) The genome sequence of the entomopathogenic bacterium

11 Photorhabdus luminescens. Nat Biotechnol 21: 1307-1313.

12 Easom, C. A. and Clarke, D. J. (2008) Motility is required for the competitive

13 fitness of entomopathogenic Photorhabdus luminescens during insect

14 infection. BMC Microbiol 8: 168.

15 ffrench-Constant, R., Waterfield, N., Daborn, P., Joyce, S., Bennett, H., Au, C., et al.

16 (2003) Photorhabdus: towards a functional genomic analysis of a symbiont

17 and pathogen. FEMS Microbiol Rev 26: 433-456.

18 Galperin, M. Y. (2004) Bacterial signal transduction network in a genomic

19 perspective. Environ Microbiol 6: 552-567.

20 Hassan, K. A., Johnson, A., Shaffer, B. T., Ren, Q., Kidarsa, T. A., Elbourne, L. D., et

21 al. (2010) Inactivation of the GacA response regulator in Pseudomonas

22 fluorescens Pf-5 has far-reaching transcriptomic consequences. Environ

$23 \quad$ Microbiol. 12: 899-915.

24 Hassett, D. J., Howell, M. L., Sokol, P. A., Vasil, M. L. and Dean, G. E. (1997)

25 Fumarase $\mathrm{C}$ activity is elevated in response to iron deprivation and in mucoid, 
1 alginate-producing Pseudomonas aeruginosa: cloning and characterization of

2 fumC and purification of native fumC. J Bacteriol 179: 1442-1451.

3 Hengge, R. (2009) Principles of c-di-GMP signalling in bacteria. Nat Rev Microbiol $4 \quad 7: 263-273$.

Hu, K. and Webster, J. M. (2000) Antibiotic production in relation to bacterial

Joyce, S. A., Brachmann, A. O., Glazer, I., Lango, L., Schwar, G., Clarke, D. J. and

9 Bode, H. B. (2008) Bacterial biosynthesis of a multipotent stilbene. Angewantde Chemie 47: 1942-1945.

11 Joyce, S. A. and Clarke, D. J. (2003) A hexA homologue from Photorhabdus regulates pathogenicity, symbiosis and phenotypic variation. Mol Microbiol

Kay, E., Dubuis, C. and Haas, D. (2005) Three small RNAs jointly ensure

secondary metabolism and biocontrol in Pseudomonas fluorescens CHA0. Proc Natl Acad Sci U S A 102: 17136-17141.

Krin, E., Derzelle, S., Bedard, K., Adib-Conquy, M., Turlin, E., Lenormand, P., et al. 8 (2008) Regulatory role of UvrY in adaptation of Photorhabdus luminescens growth inside the insect. Environ Microbiol 10: 1118-1134.

Lapouge, K., Schubert, M., Allain, F. H. and Haas, D. (2008) Gac/Rsm signal

1 transduction pathway of gamma-proteobacteria: from RNA recognition to 2 regulation of social behaviour. Mol Microbiol 67: 241-253.

3 Martin, J. F. and Liras, P. (2010) Engineering of regulatory cascades and networks controlling antibiotic biosynthesis in Streptomyces. Curr Opin Microbiol. 13: $5 \quad 263-273$. 
1 Nieselt, K., Battke, F., Herbig, A., Bruheim, P., Wentzel, A., Jakobsen, O. M., et al.

2 (2010) The dynamic architecture of the metabolic switch in Streptomyces

3 coelicolor. BMC Genomics 11: 10.

4 Pruss, B. M., Nelms, J. M., Park, C. and Wolfe, A. J. (1994) Mutations in

5 NADH:ubiquinone oxidoreductase of Escherichia coli affect growth on mixed

$6 \quad$ amino acids. J Bacteriol 176: 2143-2150.

7 Romling, U., Gomelsky, M. and Galperin, M. Y. (2005) C-di-GMP: the dawning of a

8 novel bacterial signalling system. Mol Microbiol 57: 629-639.

9 Sadykov, M. R., Mattes, T. A., Luong, T. T., Zhu, Y., Day, S. R., Sifri, C. D., et al.

10 (2010) Tricarboxylic acid cycle-dependent synthesis of Staphylococcus aureus

11 Type 5 and 8 capsular polysaccharides. J Bacteriol 192: 1459-1462.

12 Santos-Beneit, F., Rodriguez-Garcia, A., Sola-Landa, A. and Martin, J. F. (2009)

13 Cross-talk between two global regulators in Streptomyces: PhoP and AfsR

14 interact in the control of afsS, pstS and phoRP transcription. Mol Microbiol 72:

$15 \quad 53-68$.

16 Schirmer, T. and Jenal, U. (2009) Structural and mechanistic determinants of c-

17 di-GMP signalling. Nat Rev Microbiol 7: 724-735.

18 Sola-Landa, A., Moura, R. S. and Martin, J. F. (2003) The two-component PhoR-

19 PhoP system controls both primary metabolism and secondary metabolite

20 biosynthesis in Streptomyces lividans. Proc Natl Acad Sci U S A 100: 6133-

$21 \quad 6138$.

22 Somerville, G. A., Chaussee, M. S., Morgan, C. I., Fitzgerald, J. R., Dorward, D. W.,

23 Reitzer, L. J. and Musser, J. M. (2002) Staphylococcus aureus aconitase

24 inactivation unexpectedly inhibits post-exponential-phase growth and

25 enhances stationary-phase survival. Infect Immun 70: 6373-6382. 
1 Takeuchi, K., Kiefer, P., Reimmann, C., Keel, C., Dubuis, C., Rolli, J., et al. (2009)

2 Small RNA-dependent expression of secondary metabolism is controlled by

$3 \quad$ Krebs cycle function in Pseudomonas fluorescens. J Biol Chem 284: 34976-

434985.

5 Waterfield, N. R., Ciche, T. and Clarke, D. (2009) Photorhabdus and a host of hosts.

$6 \quad$ Annu Rev Microbiol 63: 557-574.

7 Watson, R. J., Joyce, S. A., Spencer, G. V. and Clarke, D. J. (2005) The exbD gene of

$8 \quad$ Photorhabdus temperata is required for full virulence in insects and symbiosis

$9 \quad$ with the nematode Heterorhabditis. Mol Microbiol 56: 763-773.

10 Williams, J. S., Thomas, M. and Clarke, D. J. (2005) The gene stlA encodes a

11 phenylalanine ammonia-lyase that is involved in the production of a stilbene

12 antibiotic in Photorhabdus luminescens TT01. Microbiology 151: 2543-2550.

13 Williams, P. and Camara, M. (2009) Quorum sensing and environmental

14 adaptation in Pseudomonas aeruginosa: a tale of regulatory networks and

15 multifunctional signal molecules. Curr Opin Microbiol 12: 182-191.

16 Wolfe, A. J. (2005) The acetate switch. Microbiol Mol Biol Rev 69: 12-50.

17 Wolfe, A. J., Chang, D.-E., Walker, J. D., Seitz-Partridge, J. E., Vidaurri, M. D., Lange,

18 C. F., et al. (2003) Evidence that acetyl phosphate functions as a global signal

19 during biofilm development. Mol Microbiol 48: 977-988.

20 Wright, J. A., Grant, A. J., Hurd, D., Harrison, M., Guccione, E. J., Kelly, D. J. and

21 Maskell, D. J. (2009) Metabolite and transcriptome analysis of Campylobacter

22 jejuni in vitro growth reveals a stationary-phase physiological switch.

$23 \quad$ Microbiology 155: 80-94. 


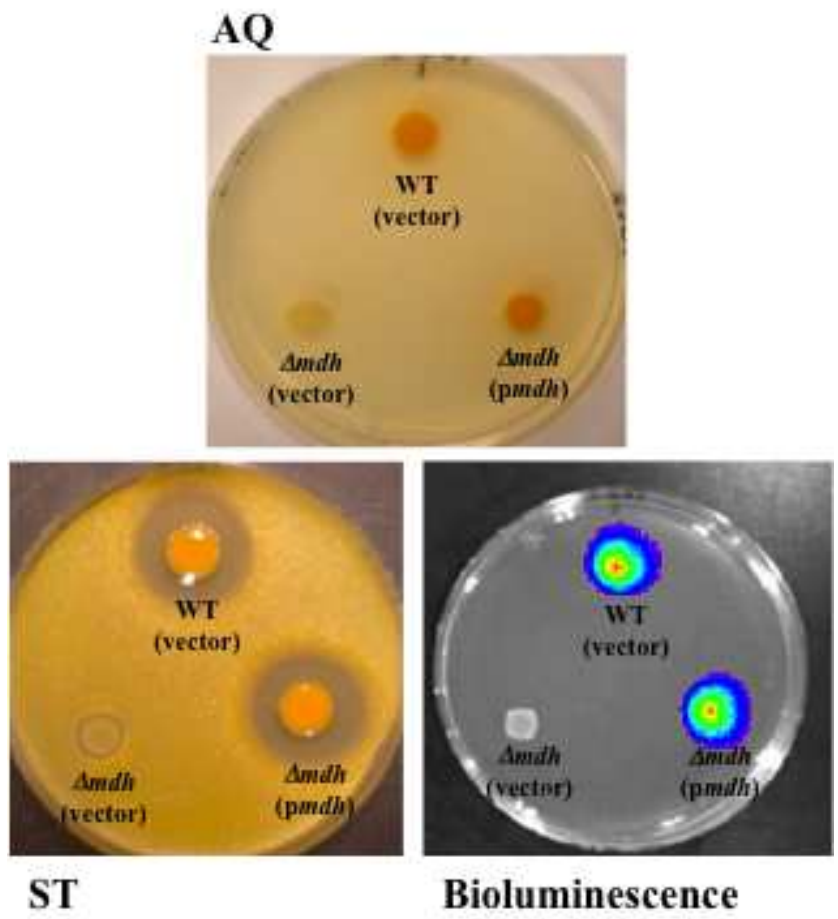

$111 \times 127 \mathrm{~mm}(72 \times 72$ DPI $)$ 
A)

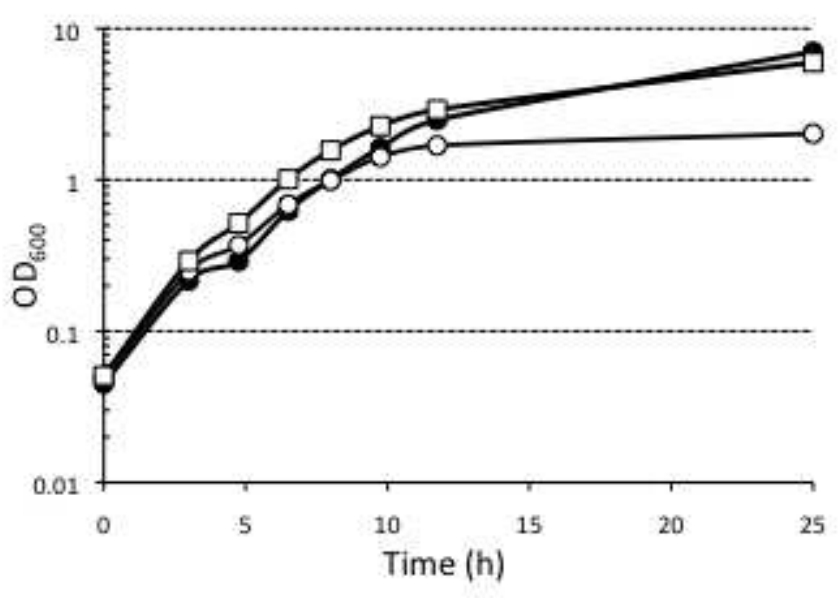

B)

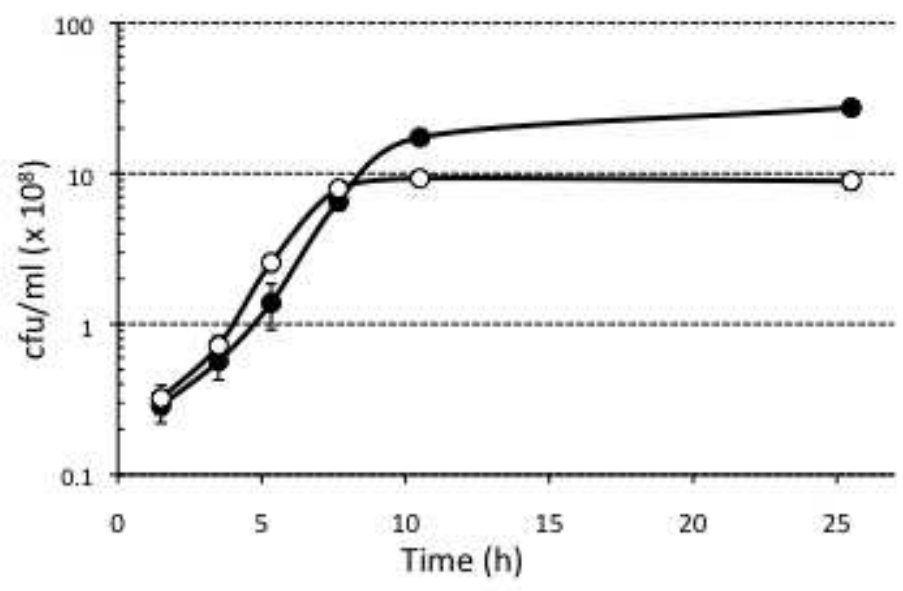

$170 \times 178 \mathrm{~mm}(72 \times 72 \mathrm{DPI})$ 


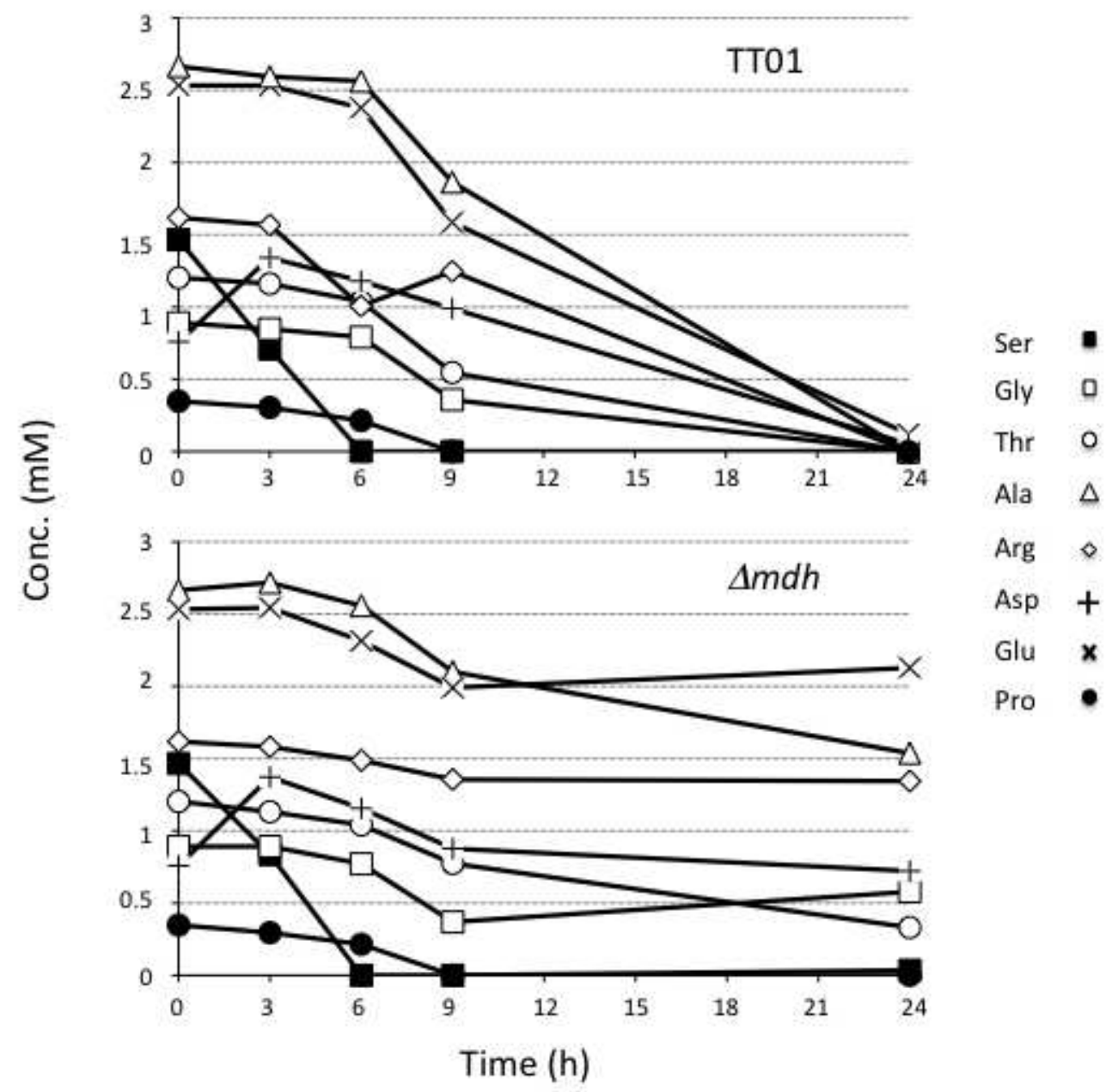

$183 \times 180 \mathrm{~mm}(72 \times 72 \mathrm{DPI})$ 


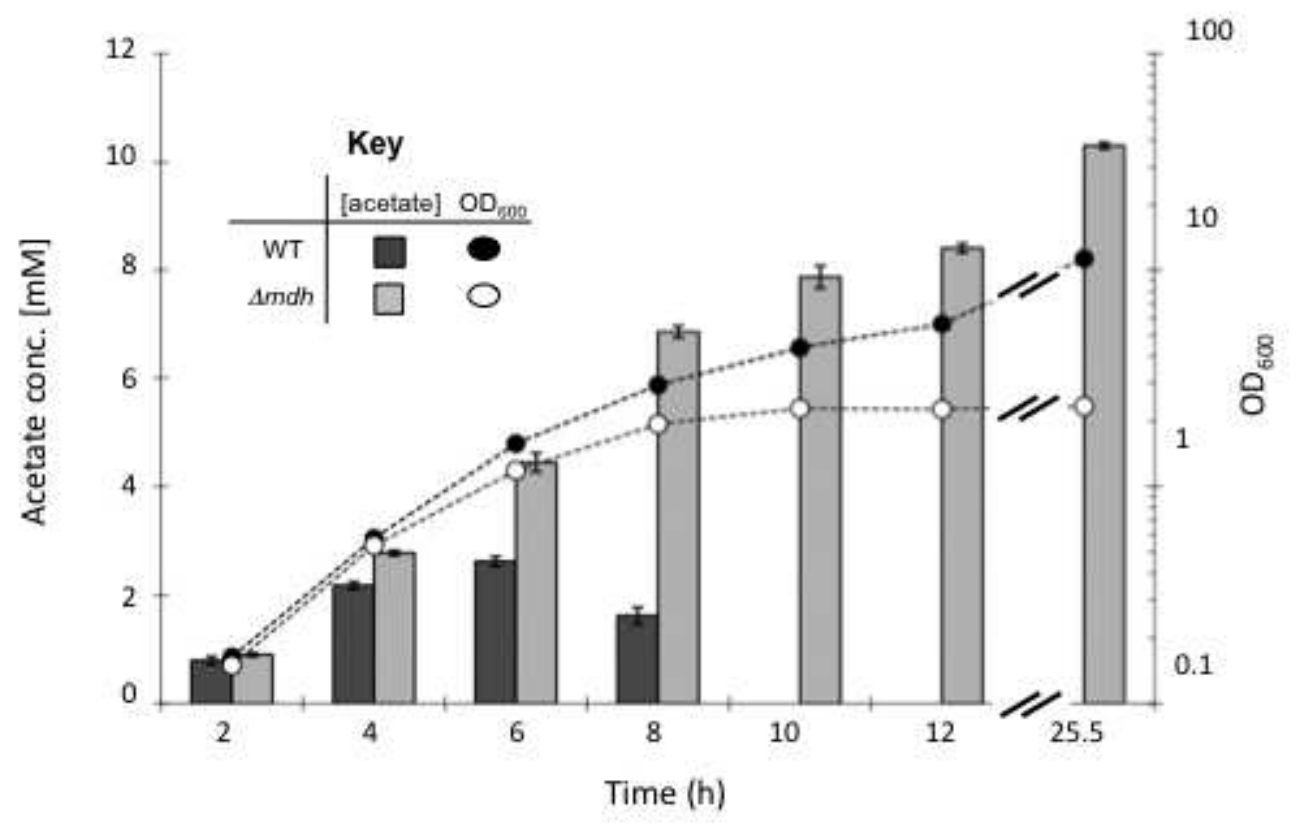

$176 \times 124 \mathrm{~mm}(72 \times 72 \mathrm{DPI})$ 
A)

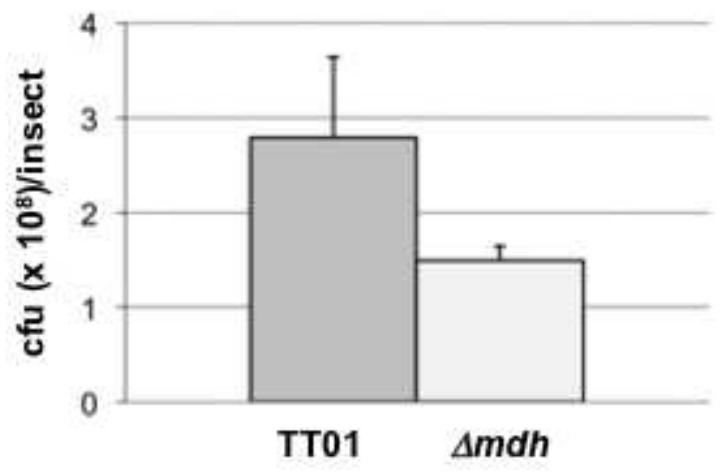

B)
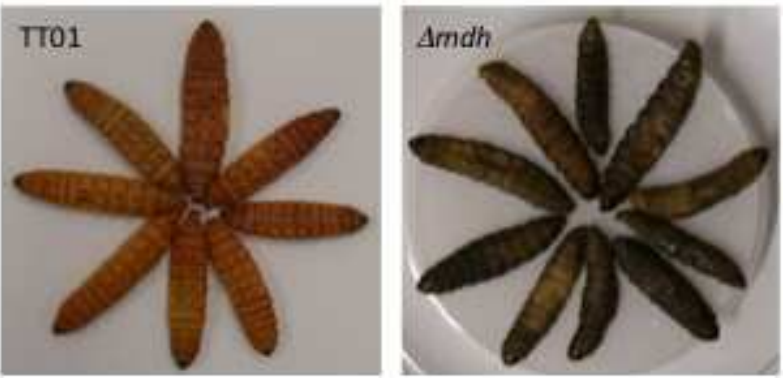

$133 \times 159 \mathrm{~mm}(72 \times 72 \mathrm{DPI})$ 

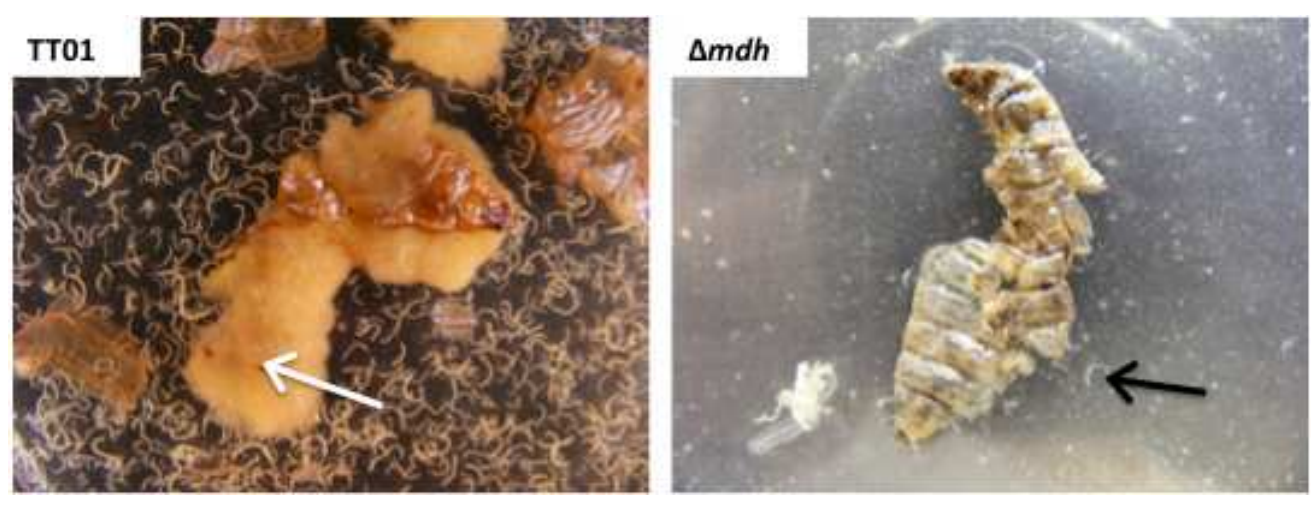

$190 \times 70 \mathrm{~mm}(72 \times 72 \mathrm{DPI})$ 